\title{
Selective Suprascapular and Axillary Nerve Block Provides Adequate Analgesia and Minimal Motor Block. Comparison with Interscalene Block
}

\section{Patrícia Falcão Pitombo* 1, Rogério Meira Barros 2, Marcos Almeida Matos ${ }^{3}$, Norma Sueli Pinheiro Módolo ${ }^{4}$}

1. MD, PhD in Anesthesiology from, Faculdade de Medicina de Botucatu, Universidade Estadual Paulista (Unesp), SP; Anesthesiologist Hospital Santa Izabel, Salvador, BA

2. MD; Master of Orthopedics and Traumatology; Coordinator of the Department of Shoulder, Hospital Santa Izabel, Salvador, BA

3. MD, PhD; Assistant Professor, Faculdade Baiana de Medicina, Salvador, BA

4. TSA; PhD; Full Professor of Anesthesiology, Faculdade de Medicina de Botucatu, Unesp, SP

Received from Hospital Santa Izabel, Salvador, BA, Brazil.

Submitted on January 28, 2012. Approved on April 11, 2012.

\begin{abstract}
Keywords: Anesthesia, Conduction; Anesthetics, Local/levobupivacaine; Brachial Plexus; Orthopedic Procedures; Shoulder Joint.
\end{abstract}

\begin{abstract}
Background and objective: Shoulder arthroscopic surgeries evolve with intense postoperative pain. Several analgesic techniques have been advocated. The aim of this study was to compare suprascapular and axillary nerve blocks in shoulder arthroscopy using the interscalene approach to brachial plexus blockade.

Methods: According to the technique used, sixty-eight patients were allocated into two groups: interscalene group (IG, $n=34$ ) and selective group ( $S G, n=34)$, with neurostimulation approach used for both techniques. After appropriate motor response, IG received $30 \mathrm{~mL}$ of $0.33 \%$ levobupivacaine in $50 \%$ enantiomeric excess with adrenalin 1:200,000. After motor response of suprascapular and axillary nerves, SG received $15 \mathrm{~mL}$ of the same substance on each nerve. General anesthesia was then administered. Variables assessed were time to perform the blocks, analgesia, opioid consumption, motor block, cardiovascular stability, patient satisfaction and acceptability.

Results: Time for interscalene blockade was significantly shorter than for selective blockade. Analgesia was significantly higher in the immediate postoperative period in IG and in the late postoperative period in SG. Morphine consumption was significantly higher in the first hour in SG. Motor block was significantly lower in SG. There was no difference between groups regarding cardiocirculatory stability and patient satisfaction and acceptability. Failure occurred in IG (1) and SG (2).

Conclusions: Both techniques are safe, effective, and with the same degree of satisfaction and acceptability. The selective blockade of both nerves showed satisfactory analgesia, with the advantage of providing motor block restricted to the shoulder.

๑ 2013 Sociedade Brasileira de Anestesiologia. Published by Elsevier Editora Ltda. All rights reserved.
\end{abstract}

* Corresponding author: Rua Almeida Couto Square, 500

Nazaré 40050-410 - Salvador, BA, Brazil

E-mail: patypf2005@yahoo.com.br

ISSN/\$ - see front metter ๔ 2013 Sociedade Brasileira de Anestesiologia. Published by Elsevier Editora Ltda. All rights reserved. 


\section{Introduction}

Shoulder arthroscopic surgeries cause severe postoperative pain ${ }^{1}$. Analgesic techniques, such as intra-articular injection of local anesthetics, parenteral opioids, brachial plexus block, and suprascapular nerve block have been used with varying effectiveness, but not without side effects ${ }^{2-5}$. Continuous intra-articular bupivacaine infusion is associated with glenohumeral chondrolysis ${ }^{2-3}$. Parenteral opioids are effective, but may result in adverse reactions, such as nausea, sedation, and dizziness ${ }^{4}$. The interscalene block technique is more effective in controlling postoperative pain, causing lower pain scores and requiring less rescue morphine ${ }^{5}$. However, it may eventually be associated with complications such as unintentional injection of local anesthetic into the epidural space, spinal cord and brachial plexus injury; or adverse effects, such as blockade of phrenic, vagus, recurrent laryngeal, stellate ganglion, and pneumothorax nerve ${ }^{6,7}$. These potential side effects and complications prompted several authors to seek options to minimize it.

The isolated suprascapular nerve block is an effective option to interscalene block ${ }^{8,9}$ during anesthesia and post-operative pain management in arthroscopic shoulder surgeries under general anesthesia, with low complication incidence $(1 \%)$, particularly pneumothorax ${ }^{10}$. Because the suprascapular nerve is not solely responsible for the sensory and motor innervation of the shoulder joint, it cannot be used as a single technique for surgical anesthesia. The axillary nerve complements the main joint innervation ${ }^{11}$.

The main objective of this prospective, randomized study was to compare the selective blockade of the suprascapular and axillary nerves with interscalene nerve block and assess the quality of analgesia, execution time of techniques, intensity of motor block, cardiovascular stability, adverse effects, patient satisfaction, acceptability of techniques, and duration of analgesia.

\section{Methods}

The institutional Ethics Committee approved the study protocol, and all patients signed the informed consent. The study design was prospective, comparative, and randomized ${ }^{12}$, conducted from June 2010 to May 2011.

After pre-anesthetic evaluation, patients were randomly assigned to two sequential and predetermined groups, and there were no technical criteria for method suspension. There was total adherence, with no dropouts during protocol. For sample size calculation, a pilot study was performed with 10 patients in each group, considering pain scores greater than three (assessed 24 hours after blockade). It was achieved in $10 \%$ of patients in the selective group (control) and in $30 \%$ of the comparison group (interscalene). Based on these findings, a sample size of 68 patients and an alpha error of $5 \%$, power of $80 \%$, and detectable difference of 0.1 between groups were estimated $(10 \%$ difference in the incidence of patients with scores greater than three).

Sixty-eight elective patients scheduled for shoulder arthroscopy surgery, aged between 18 and 80 years, both genders, ASA physical status I-II, with body mass index less than $35 \mathrm{~kg} \cdot \mathrm{m}^{-2}$, ability to understand the visual analogue pain scale, and no allergies to drugs were selected. All procedures were performed by the same anesthesiologist and same surgeon.

After monitoring with electrocardiogram (lead CM5), noninvasive blood pressure, and pulse oximetry, venipuncture with a $20 \mathrm{G}$ catheter and marking of anatomical landmarks according to the list generated by the randomization process were performed. Patients were sedated with midazolam $0.025 \mathrm{mg} . \mathrm{kg}^{-1}$ and fentanyl $1 \mu \mathrm{g} . \mathrm{kg}^{-1}$.

Two groups of 34 patients were distributed as follows: interscalene group (IG) scheduled for interscalene blockade and selective group (SG) scheduled for selective blockade of the suprascapular and axillary nerves. Blockades were performed with the aid of the neurostimulator (Stimuplex, B. Braun, Melsungen, Germany), in supine position, with a 22G, $50 \mathrm{~mm}$ needle (B. Braun, Melsungen AG, Germany) with patients in a sitting position, with $22 \mathrm{G}, 100 \mathrm{~mm}$ needle. The frequency of stimulation was $2 \mathrm{~Hz}$, amplitude $100 \mu \mathrm{s}$, intensity set to $0.5 \mathrm{~mA}$. After appropriate motor response, IG received $30 \mathrm{~mL}$ of levobupivacaine in $50 \%$ enantiomeric excess (S75: R25) at 0.33\% with epinephrine 1:200,000 after motor response of deltoid, lateral pectoral, biceps or triceps muscle. SG received $15 \mathrm{~mL}$ of the same solution in each nerve, according to the techniques: suprascapular nerve block was performed at a point approximately $2 \mathrm{~cm}$ medial to the posterolateral edge of the acromion and $2 \mathrm{~cm}$ cranial to the upper border of the scapular spine until motor response of the supraspinatus and/or infraspinatus muscles (Figure 1). Axillary nerve block was performed drawing a line that connected the anterior edge of the acromion to the inferior angle of the scapula, then a second line was drawn horizontally at its midpoint to represent the level at which the quadrangular space was identified. The puncture site was at the convergence of the second line with one that began in the posterior edge of the acromion, until deltoid motor response (Figure 2). We found that marking the anatomical landmarks facilitated the identification of nerves. We also registered the blockade duration and time for execution of techniques (defined as time elapsed from the moment of antisepsis until the needle stimulation withdrawal), presence of paresthesia, vascular puncture or other complications.

Twenty minutes after the injection of the local anesthetic, with the patient seated, sensory and motor blocks were assessed on the operated limb, using the contralateral arm as a control. Success of sensory block was assessed by loss of cold sensation in the innervation sites of respective nerves using cotton ball soaked in ether. Motor block was assessed using the modified Bromage scale 13 (grade 1 = no blocking; level 2 = unable to abduction and lateral rotation of the arm; grade 3 = complete blockade of the shoulder, arm, and forearm). Blockades were classified as adequate (defined as complete sensory and motor anesthesia of the shoulder) and inadequate (defined as partial or complete absence of sensory and/or motor anesthesia of the shoulder area). In case of failure, interscalene brachial plexus block was performed with half of the initial dose. Complications and/or adverse effects were recorded.

After the blockades, patients received general anesthesia with propofol $\left(2.0-2.5 \mathrm{mg}^{\mathrm{kg}} \mathrm{kg}^{-1}\right)$, lidocaine $2 \%$ without vasoconstrictor $\left(1 \mathrm{mg} . \mathrm{kg}^{-1}\right)$, cisatracurium $\left(0.15 \mathrm{mg} . \mathrm{kg}^{-1}\right)$, dexamethasone $5 \mathrm{mg}$, and ondansetron $4 \mathrm{mg}$. Surgeries were performed with patients in the lateral position and 


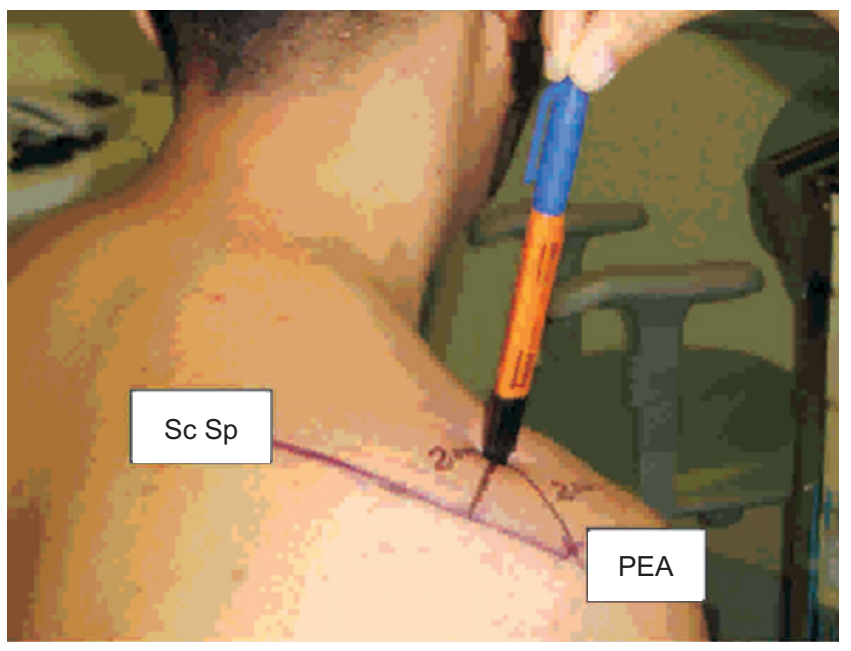

Figure 1 Suprascapular Nerve Block.

The puncture location is $2 \mathrm{~cm}$ medial to the posterior edge of the acromion (PEA) and $2 \mathrm{~cm}$ cranial to the upper border of the scapular spine (Sc. Sp).

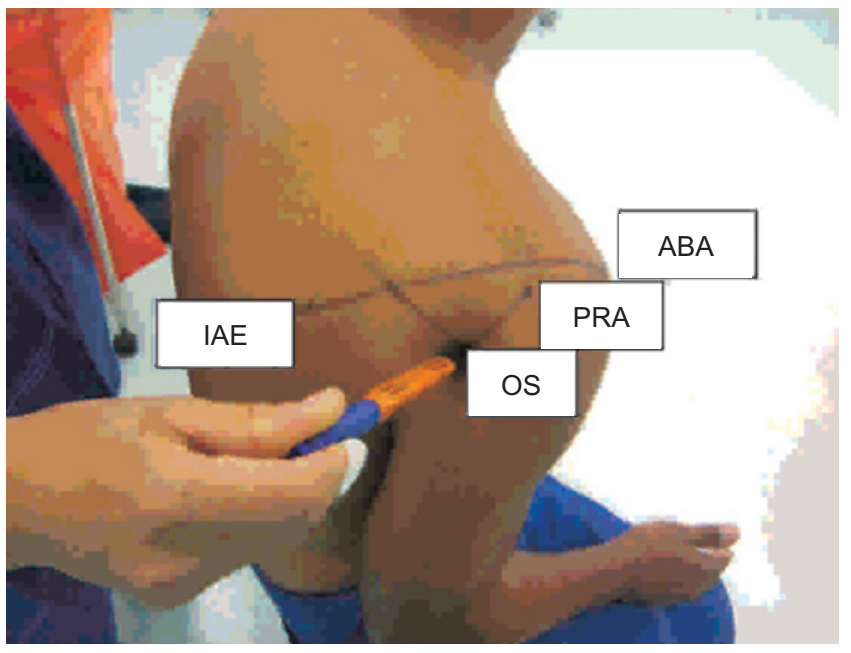

Figure 2 Axillary Nerve Block.

A line connects the anterior border of the acromion (ABA) with the inferior angle of the scapula (IAE), and then a second line is drawn horizontally at its midpoint, representing the level at which the quadrangular space (QS) is identified. Puncture location is at the convergence of the second line with another that begins at the posterior edge of the acromion (PEA).

anesthetized with sevoflurane (0.8-1.0 MAC) and 50\% nitrous oxide. Cardiovascular parameters (heart rate and systolic and diastolic blood pressures) were measured and recorded on arrival in the operating room (T1), every 5 minutes after blockade, 30 minutes after the start of surgery (T2), upon awakening (T3), and on discharge from the post-anesthesia care unit (PACU) (T4). Cardiovascular instability (BP and $\mathrm{HR}>30 \%$ from baseline of patients) was also considered a failure criterion.
Postoperative analgesia consisted of the residual effects of interscalene and selective blocks and systematic dipyrone ( $2 \mathrm{~g}$ every 6 hours IV). Pain was assessed using the visual analog scale $(0=$ no pain, $10=$ worst possible pain $)$ at times: T0 (PACU), T6 (6 hours after blockade), T12 (12 hours after blockade), and T24 (24 hours after blockade). All patients were evaluated by a physician who was not involved in the surgery. In case of moderate $(>3 \leq 6)$ or severe $(>7)$ pain, single-dose intravenous morphine $\left(0.04 \mathrm{mg} . \mathrm{kg}^{-1}\right)$ was used as rescue medication, with consumption recorded. Duration of analgesia was recorded. After 24 hours, patients were asked to rate discomfort during motor block, defined as sense of unease related to limb paralysis $(0=$ no discomfort, $10=$ maximum discomfort), and satisfaction with the techniques $(0$ = dissatisfied, $10=$ completely satisfied $)$. We also recorded the possible complications and/or side effects and if patients would accept the same anesthesia in the future (if required).

Patients were discharged 24 hours after surgery and instructed to record the time of pain onset. They were contacted by telephone 48 hours after surgery.

Data were presented in frequency distribution tables for discrete variables or mean and standard deviation for continuous variables. Comparison between variables was performed using the chi-square test for discrete variables (or Fisher's exact test when applicable) or Student $t$-test for continuous variables. The statistically significant comparisons were tested in multivariate model to identify confounding factors addressed by the evaluation of 13 magnetic resonance images (MRI). For calculation purposes, pain scores greater than three were considered. The value of $a=5 \%$ was adopted as the level of significance in all statistical tests.

\section{Results}

Demographic data, type of surgery, evaluated variables, and the respective statistical significance are shown in Table 1. The anatomical markings allowed the identification of nerves in all patients. Interscalene block was performed during $3.5 \pm 1$ minute, suprascapular block during $4 \pm 2$ minutes, and axillary block during $3 \pm 1$ minute, a statistically significant difference $(p<0.001)$.

Satisfactory sensory block assessed before the surgery and postoperatively was achieved in both groups (Table 2). In IG, we observed appropriate block in 33 patients $(97.05 \%)$, with one case of complete failure (2.94\%). In SG, adequate blockade was achieved in 31 patients $(91.18 \%)$, inadequate in one patient (partial failure of axillary nerve sensory block - 2.94\%), and complete failure in two patients $(5.88 \%)$, with no significant difference $(p=1.000)$. The duration of analgesia was statistically shorter in SG at T0 and took on an inverse relationship at T24 compared to IG (Figure 3). Only one patient $(2.94 \%)$ at T6 and two patients $(5.88 \%)$ at T12 reported moderate or severe pain in SG, and moderate pain prevailed. In IG, one patient at T6 and four patients (11.76\%) at $\mathrm{T} 12$ reported this type of pain.

Mean duration of analgesia was 20.4 hours in IG and 26.3 hours in SG ( $p=0.002$ ) (Table 2$)$. In line with the observed profile in pain scores, morphine consumption was significantly higher in SG at T0 (20/34 - 52.94\% x 4/34 - 11.7\%; p = 0.009). However, at T24, this result was not repeated, with five 
Table 1 Clinical Data, Physical Status, and Comorbidities of Patients and Type of Surgery.

\begin{tabular}{llll}
\hline Data & IG $=34$ & SG $=34$ & P \\
\hline Age $($ years $)$ & $55.03 \pm 13.04^{*}$ & $52.21 \pm 15.39^{*}$ & 0.418 \\
\hline $\begin{array}{l}\text { BMI }\left(\mathrm{kg} \cdot \mathrm{m}^{-2}\right) \\
\begin{array}{l}\text { ASA } \\
\text { I/II }\end{array}\end{array}$ & $27.95 \pm 4.35^{*}$ & $26.79 \pm 4.11^{*}$ & 0.262 \\
$\begin{array}{l}\text { Sex } \\
\text { F/M }\end{array}$ & $11 / 23$ & $17 / 17$ & 0.218 \\
$\begin{array}{l}\text { Comorbidities } \\
\text { Yes/No }\end{array}$ & $21 / 13$ & $18 / 16$ & 0.624 \\
$\begin{array}{l}\text { Surgery } \\
\text { Instability } \\
\text { Cuff injury }\end{array}$ & $25 / 09$ & $22 / 12$ & 0.600 \\
\hline
\end{tabular}

* Data expressed as mean and standard deviation; ${ }^{\text {\& }}$ surgeries associated with injuries in the same procedure; BMI: body mass index.

patients in SG (14.7\%) and 14 patients in IG (41.17\%) requiring treatment; therefore, without statistical significance $(p=0.156)$ (Figure 3$)$. The total dose of rescue medication varied between 3 and 6 mg within 24 hours in both groups (Figure 3).

There was significant difference between the degrees of motor blockade in both groups (Table 2). In SG, $94.12 \%$ of patients achieved grade 2 of motor block and $5.88 \%$ did not achieve any degree of motor block (grade 1). In IG, $58.82 \%$ achieved grade 3 of motor block and $41.18 \%$ grade 2 . Motor blockade discomfort showed a $\mathrm{p}<0.001$, which may be explained by the almost absolute no complaints of discomfort related to limb paralysis by patients in SG $(03 / 34-8.82 \%)$, contrary to the high incidence seen in IG (17/34 - 50\%) (Table II).

Cardiocirculatory stability (SBP, DBP and HR) occurred in both groups, without statistical significance (Figure 4 and Figure 5, T2).

There were no complications (pneumothorax, local anesthetic injection into the epidural space) and/or adverse effects (recurrent laryngeal and stellate ganglion, venipuncture, seizures, paresthesia) during blockades. The incidence of nausea and vomiting was $11.8 \%$ in SG and $17.65 \%$ in IG, with no significant difference $(p=0.961)$.
Satisfaction with the technique was similar in both groups and not statistically significant (Table 2). Two patients in IG and one patient in SG reported they would undergo the same anesthetic technique again.

Confounding factors were not statistically significant (Table 3). Patients were discharged 24 hours after surgery and released for passive elbow and hand physiotherapy.

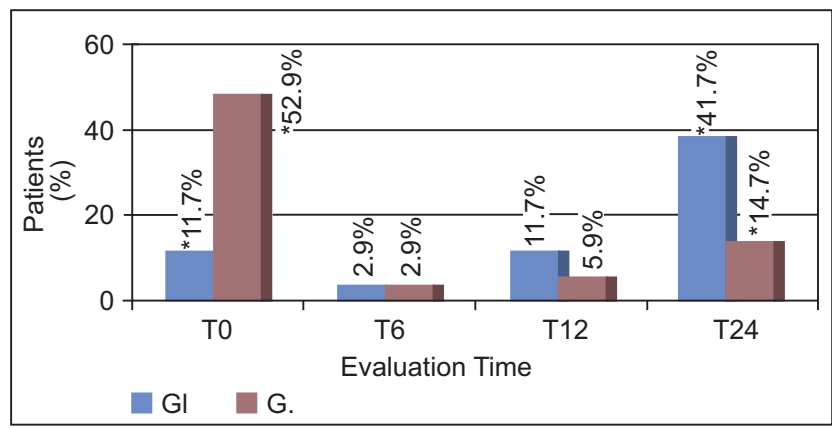

Figure 3 Percentage of Patients with Pain Score $>3$ and Morphine Consumption at Different Times in Both Groups.

Table 2 Sensory Block, Motor Block, Duration of Analgesia, Discomfort, and Satisfaction.

\begin{tabular}{llll}
\hline & IG $=34$ & SG $=34$ & P \\
\hline Sensory block & 33 & 31 & 1.000 \\
$\quad$ Adequate & 00 & 01 & \\
$\quad$ Inadequate & 01 & 02 & $<0.001$ \\
$\quad$ Complete failure & & 00 & \\
Motor block & 20 & 31 & 0.002 \\
$\quad$ Total & 13 & 03 & $<0.001$ \\
Partial & 01 & $26.3 \pm 7.7$ & 0.979 \\
Absent & $20.4 \pm 6.8$ & $0.5 \pm 1.48$ & \\
Duration of Analgesia $\left(^{*}\right)$ & $3.43 \pm 3.87$ & $9.21 \pm 1.53$ & \\
Discomfort $\left(^{*}\right)$ & $9.20 \pm 1.53$ & & \\
Satisfaction $\left(^{*}\right)$ & & & \\
\hline
\end{tabular}




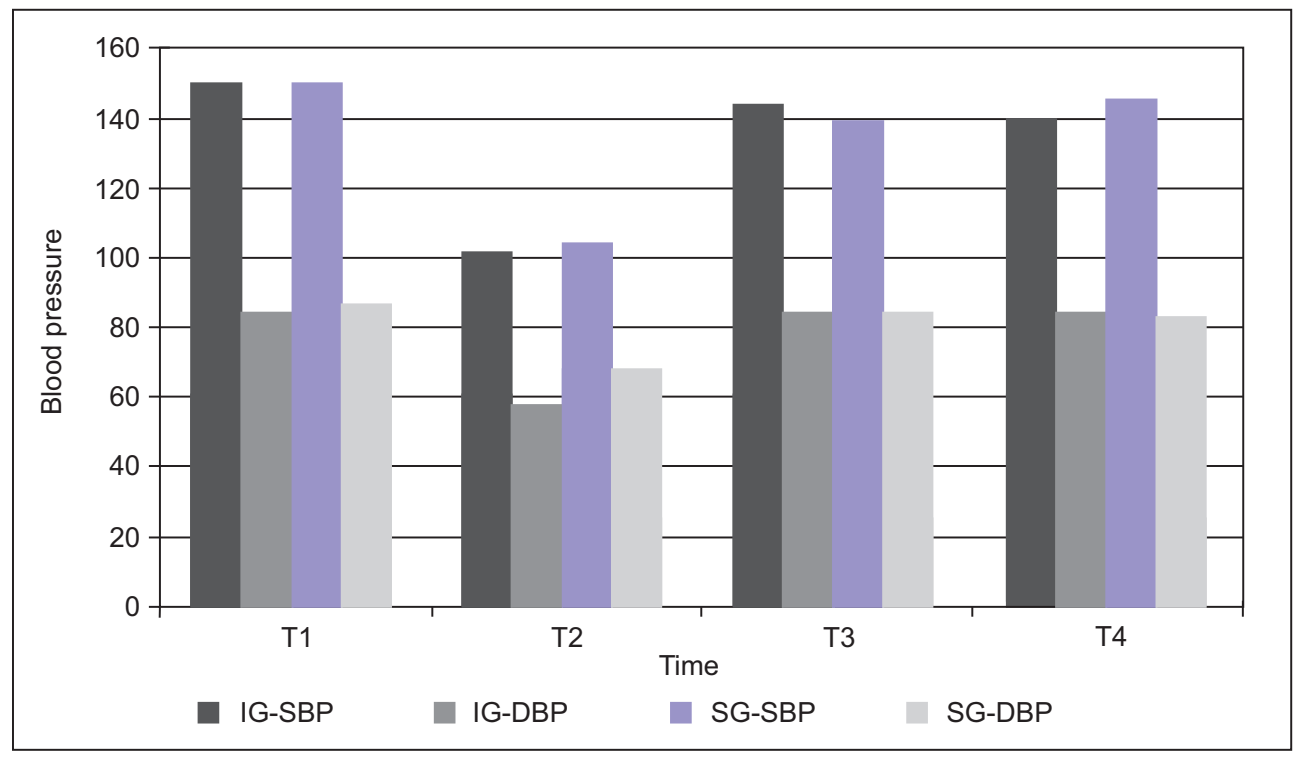

Figure 4 Systolic and Diastolic Blood Pressure Values $(\mathrm{mm} \mathrm{Hg})$ Expressed as Mean According to Groups and Evaluation Times.

\section{Discussion}

Selective blockade of the suprascapular and axillary nerves was easy to perform, with less analgesia in the immediate postoperative period, lower incidence of motor block, longer time to perform it, prolonged analgesia in the postoperative period and the same level of satisfaction, incidence of complications and/or adverse effects, compared to interscalene block, which is the technique most widely used for shoulder procedures. It was not the object of study to select the two techniques based on surgical procedures.

The shoulder rotator cuff consists of tendons from four muscles: supraspinatus, infraspinatus, subscapularis, and teres minor ${ }^{14}$. The suprascapular nerve is responsible for supplying $70 \%$ of sensory and motor coordination, which includes the upper, medial, and posterior joint regions, posterior

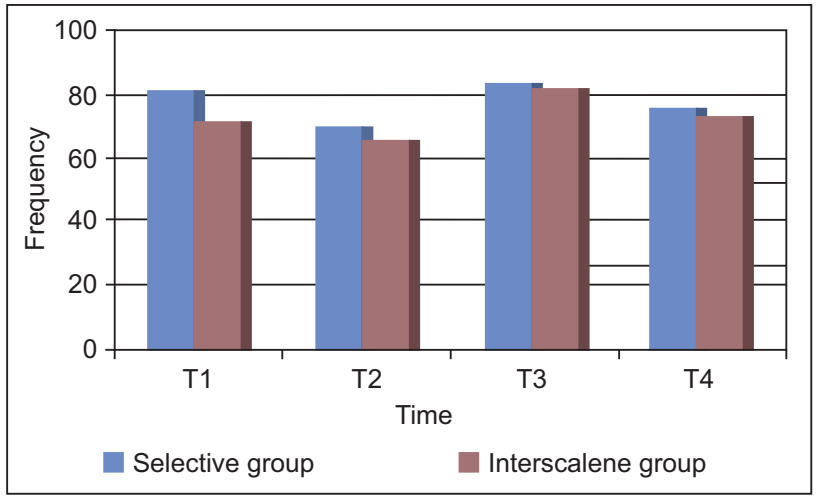

Figure 5 Heart Rate Values (beat. min ${ }^{-1}$ ) Expressed as Mean According to Groups and Evaluated Times.

Table 3 Multivariate Analysis of Clinical and Demographic Factors Associated with Pain.

\begin{tabular}{|c|c|c|c|}
\hline Confounding Factors & Mild & Moderate/Severe & $p$ \\
\hline Sex & & & 0.391 \\
\hline Male & 22 & 6 & \\
\hline Female & 25 & 13 & \\
\hline Type of Surgery & & & 0.648 \\
\hline Cuff & 30 & 12 & \\
\hline Other & 10 & 2 & \\
\hline Use of Opioids & & & 1.000 \\
\hline No & 25 & 9 & \\
\hline Yes & 24 & 10 & \\
\hline Motor Block Discomfort & & & 0.168 \\
\hline No & 34 & 10 & \\
\hline Yes & 12 & 9 & \\
\hline Satisfaction & & & 0.274 \\
\hline Satisfied & 45 & 16 & \\
\hline Unsatisfied & 0 & 1 & \\
\hline Subscapular Injury* & & & 1.000 \\
\hline No & 5 & 1 & \\
\hline Yes & 4 & 2 & \\
\hline
\end{tabular}

* Test performed in 13 patients. 
capsule, acromioclavicular joint, subacromial bursa, and coracoclavicular ligament and, variably, the skin around these regions ${ }^{11}$. The axillary nerve complements the main innervation, positioned laterally to the radial nerve and entering the quadrangular space, where it divides into two branches: the anterior branch innervates the middle and anterior portion of the deltoid muscle and the posterior branch innervates the teres minor and the posterior fibers of this muscle and terminates as the arm lateral superior cutaneous nerve ${ }^{11,15}$. Compared to the interscalene blockade, which blocks the entire shoulder girdle and upper limb, the selective block is limited to the supraspinatus, infraspinatus, and teres minor muscles, preserving the arm, forearm, and hand muscles ${ }^{15}$. Subscapularis muscle and the anterior glenohumeral joint capsule, supplied by the subscapular nerve, are not anesthetized by the selective technique ${ }^{11}$.

Anatomical markings and peripheral nerve stimulator were used in both groups. The time found for blockades in SG (6 min) was nearly twice that of the interscalene block ( $3.5 \mathrm{~min}$ ), which could be explained by the use of two specific and independent accesses. There is a report of another lateral approach that directs the needle medial and anteriorly to the convergence of the spine and clavicle ${ }^{8}$. In this study, we used the modified lateral approach ${ }^{18}$, similar to another method $^{8}$, which had the same insertion location, but the needle is positioned posteriorly $\left(70^{\circ}\right.$ angle to the skin in a horizontal plane) towards the scapular spine, which makes the bevel contact the supraspinous fossa or the scapular spine ventral wall. Consequently, the injected solution is directed to the suprascapular notch and takes the fossa's concavity. This study confirms previous study in which there were no complications, such as pneumothorax, suprascapular nerve injury, and hematoma ${ }^{8,18}$. In the axillary nerve approach, local anesthetic was deposited into the quadrangular space, before its division ${ }^{15}$.

Satisfactory sensory block (assessed before surgery and postoperatively) and cardiocirculatory stability (assessed at four time points) proved the analgesic efficacy of both techniques. Because the suprascapular nerve is predominantly motor ${ }^{14}$, without cutaneous sensory components, the sensory test with ether was ineffective; thus, motor function was used as a tool for assessing blockade effectiveness.

Contrary to other authors ${ }^{11}$ who reported pain after 6 hours postoperatively, we found a high incidence of pain in the PACU in SG (52.94\%), which, if compared to IG $(11.7 \%)$ was significant. This suggests that blocking the entire brachial plexus is most effective in the immediate postoperative period. Factors, such as randomization of the study (subscapularis tendon and anterior glenohumeral capsule are not anesthetized ${ }^{11}$ ) and anterior capsular distension caused by the use of intra-articular saline, explain the higher initial pain scores in SG. From the second postoperative hour (with edema absorption), this ratio equaled and/or reversed in relation to the interscalene group (mean duration of analgesia 20.4 hours), which showed that SG achieved more prolonged analgesia in the postoperative period (mean duration of analgesia 26.3 hours, $p=0.002$ ). This reflected in higher morphine consumption in SG during PACU stay $(52.942 \%)$ compared to the interscalene group (11.7\%). However, from the sixth hour, consumption equaled and reversed from the $12^{\text {th }}$ hour.
The non-significance seen during the test of confounding factors regarding analgesia also proves the effectiveness of both techniques.

Some types of injuries cause supraspinatus tendon retraction; consequently, suprascapular nerve undergoes modification from its original position ${ }^{19,20}$. The two failures in selective group occurred by difficulty in locating this nerve due to retraction imposed by the type of rotator cuff injury. The only failure recorded in the interscalene group was due to technical difficulties (overweight and very short neck patient). All failures were solved with new interscalene approach to brachial plexus, with half of the initial dose.

Phrenic nerve block occurs in all patients with the use of interscalene technique ${ }^{21,22}$. We had no opportunity to test selective blockade in patients with respiratory diseases. However, because in this technique the needle is introduced distant from the pleura and nerves involved in breathing (phrenic and recurrent laryngeal nerve), it is possible to predict that this blockade is associated with minimal risk of respiratory complications, confirmed by a study of the same technique ${ }^{11}$. Therefore, it would be interesting to consider this approach in patients with absolute contraindication to any degree of phrenic nerve block.

There were no complications during and after blockades in both groups, confirming the safety of the interscalene and selective techniques.

Radial nerve block occurred in $5 \%$ of female patients ${ }^{15}$, a value much lower than that found in this work (characterized by mild sensory block), which was $17.6 \%$ (five women and one man). This result indicates that indeed there may be sufficient spreading of local anesthetic to the posterior cord of the brachial plexus when suprascapular nerve block is performed, particularly in patients of small stature. It is likely that by decreasing the anesthetic volume such occurrences may decrease ${ }^{15}$.

The low incidence of nausea and vomiting was due to the use of opioids at low doses and dipyrone alone in the postoperative period. The few related cases may be attributed to the use of inhaled agents.

Despite the excellent tolerance, two patients in the interscalene group reported that, if there were another option, they would not undergo the same anesthesia again because of the unpleasant presence of residual motor blockade. In SG, only one patient reported the same opinion because of nausea and vomiting.

Our study had limitations. We used only 13 of 34 RM images performed in the selective group to assess the significance of subscapularis muscle injury in the occurrence of pain; we did not record the amount of saline solution used in each procedure by the surgeon, which could cause distention of the glenohumeral anterior capsule and influence pain score assessment. Because of erroneous initial evaluation, patients with recurrent scapulohumeral dislocation were not excluded, whose approach includes repair of the anterior capsule and/or subscapularis muscle. However, despite the small number of cases, the assessment of confounding factors regarding type of surgery and occurrence of pain was not statistically significant.

Both techniques (interscalene and selective) are effective and safe in arthroscopic shoulder surgery. The selective technique advantages regarding interscalene brachial plexus 
block include the ability to move the arm, forearm, and hand (which prevents the motor block of upper areas innervated by the lower roots of the brachial plexus ${ }^{23}, \mathrm{C} 8-\mathrm{T} 1$ ), prevention of adverse effects (particularly phrenic nerve block, which makes the technique quite attractive for patients with pulmonary disease) and associated complications.

The understanding of anatomy, complications, contraindications, and technique limitations allows the anesthesiologist to choose the best technique to provide quality anesthesia in arthroscopic shoulder surgeries. In conclusion, regarding interscalene block, the selective blockade of the suprascapular and axillary nerves provides less analgesia in the immediate postoperative period, more prolonged analgesia in the postoperative period, motor block restricted to the shoulder, minor discomfort associated with upper limb paralysis, similar satisfaction and acceptability, without phrenic nerve block.

\section{Acknowledgments}

We would like to thank our friend, Professor Luiz Eduardo Imbelloni, for his suggestions that have enriched this work and teachings that made our journey richer.

\section{References}

1. Fredrickson MJ, Krishnan S, Chen CY - Postoperative analgesia for shoulder surgery: a critical appraisal and review of current techniques. Anaesthesia, 2010;65:608-624.

2. Busfield BT, Romero DM - Pain pump use after shoulder arthroscopy as a cause of glenohumeral chondrolysis. Arthroscopy, 2009;25:647-652.

3. Hansen BP, Beck CL, Beck EP, Townsley RW - Postarthroscopic glenohumeral chondrolysis. Am J Sports Med, 2007;35:16281634.

4. Watcha MF, White PF - Postoperative nausea and vomiting. Its etiology, treatment, and prevention. Anesthesiology, 1992;77:162-184.

5. Singelyn FJ, Lhotel L, Fabre B - Pain relief after arthroscopic shoulder surgery: a comparison of intraarticular analgesia, suprascapular nerve block, and interscalene brachial plexus block. Anesth Analg, 2004;99:589-592.

6. Balas GI - Regional anesthesia for surgery on the shoulder. Anesth Analg, 1971;50:1036-1041.

7. Wedel DJ - Nerve blocks. In: Miller RD (Ed.). Miller's Anesthesia $4^{\mathrm{a}}$ ed. New York: Churchill Livingstone, 1994, pp. 1535-1564.
8. Barber FA - Suprascapular nerve block for shoulder arthroscopy. Arthroscopy, 2005;21:1015.

9. Emery $\mathrm{P}$ - Suprascapular nerve block for chronic shoulder pain in rheumatoid arthritis. Br Med J, 1989;299:1079-1080.

10. Vecchio PC, Adebajo AO, Hazleman BL - Suprascapular nerve block for persistent rotator cuff lesions. J Rheumatol, 1993;20:453-454.

11. Checcucci G, Allegra A, Bigazzi P, Gianesello L, Ceruso M, Gritti $\mathrm{G}$ - A new technique for regional anesthesia for arthroscopic shoulder sugery based on a suprascapular nerve block and an axillary nerve block: an evaluation of the first results. Arthroscopy, 2008;24:689-696.

12. Programa Pepi [Computer programs for epidemiologists] by J.H. Abramson and Paul M. Gahlinger, Version 4.04x.

13. Bromage PR - A comparasion of the hydrochloride and carbon dioxide salts of lidocaine and prilocaine in epidural analgesia. Acta Anaesthesiol Scand, 1965;16(Suppl):55-69.

14. Thompson JC - Atlas de anatomia ortopédica de Netter. Porto Alegre: Artmed, 2004, pp. 66-69.

15. Price DJ -The shoulder block: a new alternative to interscalene brachial plexus blockade for the control of postoperative shoulder pain. Anaesth Intensive Care, 2007;35:575-581.

16. Roark GL - Suprascapular nerve block at the spinoglenoid notch. Reg Anesth Pain Med, 2003;28:361-362.

17. Meier G, Bauereis C, Maurer $\mathrm{H}$ - The modified technique of continuous supraescapular nerve block. A safe technique in the treatment of shoulder pain. Anaesthesist, 2002;51:747-753.

18. Feigl GC, Anderhuber F, Dorn C et al. - Modified lateral block of the suprascapular nerve: a safe approach and how much to inject? A morphological study. Reg Anesth Pain Med, 2007;6:32:488-494.

19. Mallon WJ, Wilson RJ, Basamania MD - The association of supraescapular neuropathy with massive rotator cuff tears: a preliminary report. J Shoulder Elbow Surg, 2006;15:395-398.

20. Warner JP, Krushell RJ, Masquelet A, Gerber C - Anatomy and relationships of the suprascapular nerve: anatomical constraints to mobilization of the supraspinatus and infraspinatus muscles in the management of massive rotator-cuff tears. J Bone Joint Surg Am, 1992;74:36-45.

21. Pere $P$, Pitkänen $M$, Rosenberg $P H$ et al. - Effect of interscalene plexus block on diaphragmatic motion and on ventilatory function. Acta Anaesthesiol Scand, 1992;36:53-57.

22. Kempen PM, O'Donnel J, Lawler R, Mantha V - Acute respiratory insufficiency during interscalene plexus block. Anesth Analg, 2000;90:1415-1416.

23. Rothe C, Asghar S, Andersen HL et al. - Ultrasound-guided block of axillary nerve: a volunteer study of a new method. Acta Anaesthesiol Scand, 2011;55:565-570. 